\title{
Evaluation of Carbon Paste Electrodes Modified with Organic Molecules for the Analysis of Heavy Metals by Square Wave Voltammetry
}

Hambate Gomdje Valery ${ }^{1,3}$, Thérèse Rosie Ngono ${ }^{1}$, Hind Saâdane ${ }^{1}$, Madiha Ennachete ${ }^{1}$, Mostafa Khouili², Abdrrafia Hafid ${ }^{2}$, Loura Benoît ${ }^{3}$ and Abdelilah Chtaini ${ }^{1 *}$

${ }^{1}$ Equipe of Molecular Electrochemistry and Inorganic Materials, Sultan Moulay Slimane University, Faculty of Science and Technology of Beni Mellal, Morocco ${ }^{2}$ Laboratory of Organic and Analytical Chemistry, Sultan Moulay Slimane University, Faculty of Science and Technology of Beni Mellal, Morocco ${ }^{3}$ Higher Institute of the Sahel, University of Maroua, Cameroon

\begin{abstract}
Three organic molecules were used as modifiers of carbon paste electrodes (CPEs) for the analysis of different metals $\left(\mathrm{Pb}^{2+}, \mathrm{Cd}^{2+}\right.$ and $\left.\mathrm{Cu}^{2+}\right)$ by using Square Wave Voltammetry (SWV) technique. The effect of the modified electrodes (MO-CPEs) on the electrochemical behavior has been shown. The MO-CPEs gives the more sensitivity. The detection limits obtained in all analysis approaching $10^{-8} \mathrm{~mol} / \mathrm{L}$.
\end{abstract}

Keywords: Chemically modified carbon paste electrode; Square wave voltammetry; Heavy metals

\section{Introduction}

In recent years electrochemical sensors has been widely applied due to the advantages such as high sensitivity, rapidity of response, simplicity, low cost, miniaturized and automated devices [1,2]. The research activities in the preparation of electrochemical sensors for detecting heavy metals have dramatically increases over the past decades with the development of new materials and novel fabrication process $[3,4]$.,

Recently assembly of organic layers onto surfaces have been widely used in constructing the electrochemical sensors due to their unique characteristics such as high surface area and strong adsorption ability.

Carbon paste electrodes chemically modified are endowed with many good qualities, such as ease of handling and applicability to anodic oxidations [5,6]. Different modifiers for carbon paste have been reported in the last years for the electrochemical stripping analysis of heavy metals.

Recently, methods involving radical-based mechanisms have been developed for the modification of carbon surfaces with covalently attached layers of organic species. The deposition of mono or multilayers at the carbon paste surfaces serves the purpose of electrode functionalization for analytical purposes, like electro analysis of heavy metals [7].

In this paper, a novel electrochemical sensor was developed by incorporation of organic molecules into the paste carbon electrode. These electrodes were used for the chemical preconcentration of different heavy metals at trace levels. The organic molecules modified carbon paste electrode (MO-CPE) can preconcentrate heavy metals from aqueous solution to the surface of the modified CPE by forming complexes with these ions and greatly increasing the sensitivity of its determination. The experimental data show that some of the MO-CPEs have high sensitivity, adequate selectivity and reproducibility, and a wide operative linear range of concentrations for the determination of heavy metals in water samples. The MO-CPEs have the advantages of simple methods of synthesis and purification and their low solubility in water.

\section{Experimental}

\section{Reagents and chemicals}

All chemicals were of the highest quality. Graphite powder (spectroscopic grade RWB, Ringsdorff-Werke GmbH, Bonn-Bad Godesberg, Germany) was obtained from Aldrich and was used without further purification. $\mathrm{CuSO}_{4}, \mathrm{PbSO}_{4}$ and $\mathrm{CdSO}_{4}$ were obtained from Merck chemicals. Deionised water was used to prepare all solution. All organic molecules were synthesised in our laboratory.

\section{Apparatus}

Electrochemical experiments were performed using a voltalab potentiostat (model PGSTAT 100, Eco Chemie B.V., Utrecht, The Netherlands) driven by the general purpose electrochemical systems data processing software (voltalab master 4 software).

All the electrochemical experiments were performed in a standard one-compartment three-electrode cell. The reference electrode was SCE and the counter electrode was platinum. All electrode potentials were referred to this reference electrode. The working electrode was MO-CPE.

\section{Electrode preparation}

The carbon paste unmodified was prepared by adding paraffin oil to carbon powder. Organic molecules-modified carbon paste electrodes (MO-CPEs) were prepared by substituting corresponding amounts of the carbon powder by the organic molecules and the adding the paraffin oil and thoroughly hand-mixing in a mortar and pestle. The resulting

${ }^{*}$ Corresponding author: Abdelilah Chtaini, Equipe of Molecular Electrochemistry and Inorganic Materials, Sultan Moulay Slimane University, Faculty of Science and Technology of Beni Mellal, Morocco, Tel: +212523485112; Fax: +212523485201 E-mail: a.chtaini@usms.ma

Received June 17, 2013; Accepted October 30, 2013; Published November 04 2013

Citation: Valery HG, Ngono TR, Saâdane H, Ennachete M, Khouili M, et la. (2013) Evaluation of Carbon Paste Electrodes Modified with Organic Molecules for the $\$$ nalysis of Heavy Metals by Square Wave Voltammetry. Pharmaceut Anal Acta 4: 271. doi: $10.4172 / 2153-2435.1000271$

Copyright: @ 2013 Valery HG, et al. This is an open-access article distributed under the terms of the Creative Commons Attribution License, which permits unrestricted use, distribution, and reproduction in any medium, provided the original author and source are credited. 
paste was packed into the electrode and the surface was smoothed. The organic molecules used as modifiers are presented in Figure 1.

The molecule $(\mathrm{A})$ is very similar to that given in literature [8], including the diazonium reduction in the electrochemical measuring cell. The diazonium exchange one electron with the electrode surface and turns to an aryl radical; the latter establishes a covalent bond with the surface of electrode.

We find that other molecules (B and C) follow the same mechanism and lead to the formation of an organic film on the electrode surface.

The cyclic voltammograms (CVs) of the MO-CPE and CPEs were recorded in the supporting electrolyte. In cycles between -1.5 and $1.5 \mathrm{~V}$, no redox peaks were observed (Figure 2).

The CVs of the CPEs modified with molecules A, B and C show small differences (Figures 3 and 4).

The change of the CVs shapes, before and after modification, is a major sign that the carbon paste surface is modified.
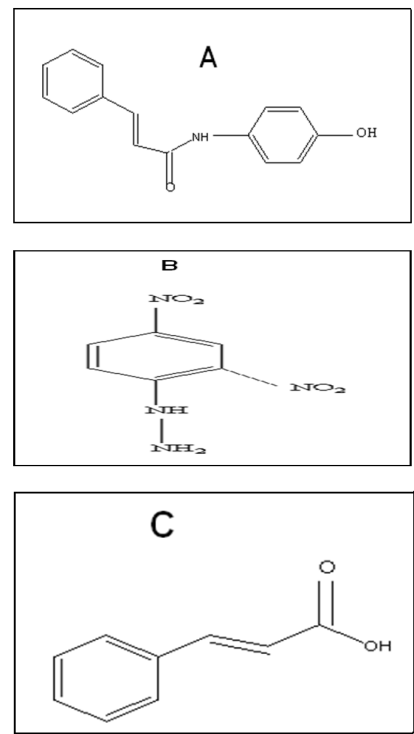

Figure 1: Organic molecules used as modifiers.

\begin{tabular}{|l|l|}
\hline Parameters & $\mathrm{Pb}(\mathrm{II})$ \\
\hline Equation & $35.76[\mathrm{~Pb}(\mathrm{II})]\left(\mu \mathrm{mol} \mathrm{I}^{-1}\right)+0.0295$ \\
\hline $\mathrm{R}^{2}$ & 0.9852 \\
\hline Pente $\left(\mathrm{mol} \mathrm{L}^{-1}\right)$ & 35.76 \\
\hline D.L. $\left(\times 10^{7} \mathrm{~mol} \mathrm{~L}^{-1}\right)$ & 5.7 \\
\hline Q.L. $\left(\times 10^{-6} \mathrm{~mol} \mathrm{~L}^{-1}\right)$ & 6.23 \\
\hline R.S.D $(\%)$ & $6.8 \%$ \\
\hline
\end{tabular}

Table 1: Parameters obtained from the calibration plot, for CPE modified by molecule A.

\begin{tabular}{|l|l|}
\hline Parameters & Cd (II) \\
\hline Equation & $75.23[\mathrm{Cd}(\mathrm{II})]\left(\mu \mathrm{mol} \mathrm{l}^{-1}\right)+0.075$ \\
\hline $\mathrm{R}^{2}$ & 0.9802 \\
\hline Pente $\left(\mathrm{mol} \mathrm{L}^{-1}\right)$ & 75.23 \\
\hline D.L. $\left(\times 10^{6} \mathrm{~mol} \mathrm{~L}^{-1}\right)$ & 8.24 \\
\hline Q.L. $\left(\times 10^{6} \mathrm{~mol} \mathrm{~L}^{-1}\right)$ & 7.43 \\
\hline R.S.D $(\%)$ & $5.0 \%$ \\
\hline
\end{tabular}

Table 2: Parameters obtained from the calibration plot, for CPE modified by molecule B.

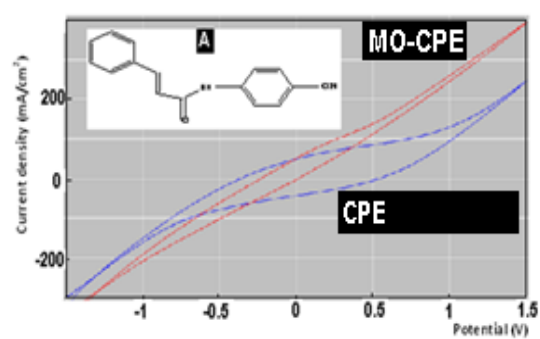

Figure 2: Cyclic voltammograms obtained by $\mathrm{MO}=\mathrm{A} C P E s$ and $\mathrm{CPE}$ at $100 \mathrm{mV} / \mathrm{s}$ in buffer solution.

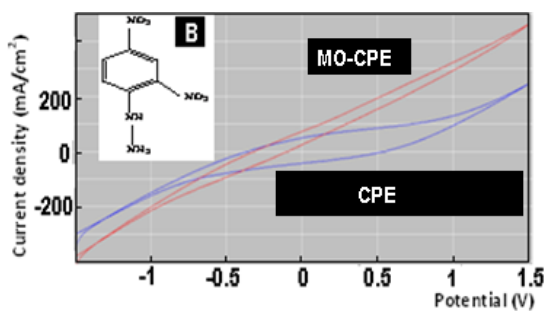

Figure 3: Cyclic voltammograms obtained by $\mathrm{MO}=\mathrm{B}$ CPEs and $\mathrm{CPE}$ at $100 \mathrm{mV} / \mathrm{s}$ in buffer solution.

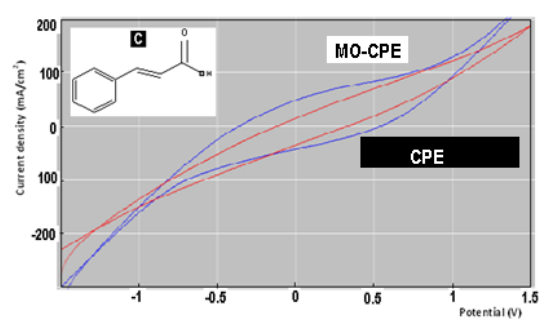

Figure 4: Cyclic voltammograms obtained by $\mathrm{MO}=\mathrm{C}$ CPEs and $\mathrm{CPE}$ at $100 \mathrm{mV} / \mathrm{s}$ in buffer solution.

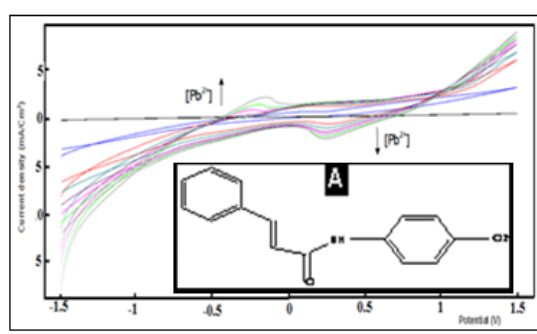

Figure 5: Cyclic voltammograms obtained by $\mathrm{MO}=\mathrm{A}$ CPEs at $100 \mathrm{mV} / \mathrm{s}$ for different concentrations of lead, in buffer solution.

Figure 5 shows $\mathrm{CV}$ s for $\mathrm{Pb}(\mathrm{II})$ solutions obtained at $\mathrm{CPE}$ modified with molecule $\mathrm{A}$. The cathodic scan produces the reduced species of lead, which is deposited on the electrode. This deposition favours the oxidation process and hence the current peak of this signal (i.e., the anodic peak).

The peak current increased with an increase in $\mathrm{Pb}^{2+}$ concentration.

Figures 6 and 7 show CVs, respectively, for Cd(II) solution obtained at $\mathrm{CPE}$ modified with molecule $\mathrm{B}$ and $\mathrm{Cu}(\mathrm{II})$ obtained at $\mathrm{CPE}$ modified with molecule $\mathrm{C}$. 


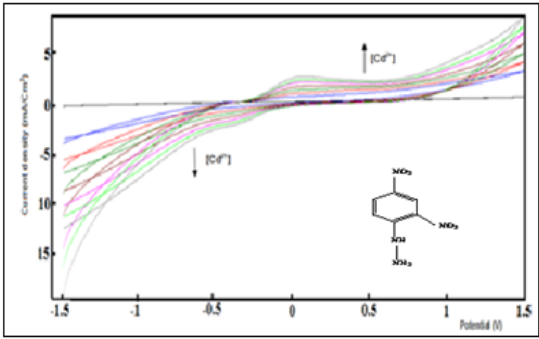

Figure 6: Cyclic voltammograms obtained by MO=B CPEs at $100 \mathrm{mV} / \mathrm{s}$ for different concentrations of $\mathrm{Cd}(\mathrm{II})$, in buffer solution.

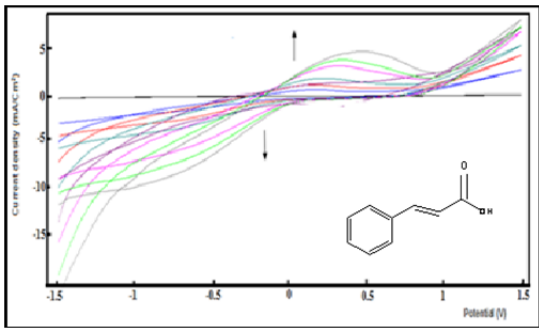

Figure 7: Cyclic voltammograms obtained by $\mathrm{MO}=\mathrm{C}$ CPEs at $100 \mathrm{mV} / \mathrm{s}$ for different concentrations of $\mathrm{Cu}$ (II), in buffer solution.

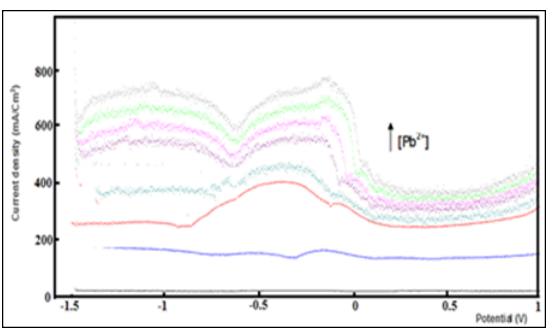

Figure 8: Square wave voltammograms obtained for CPE modified by molecule A, for different concentrations of palladium.

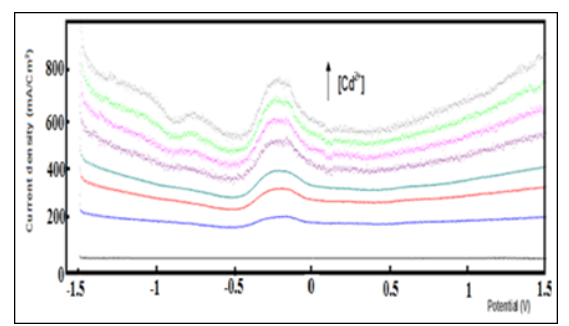

Figure 9: Square wave voltammograms obtained for CPE modified by molecule B, for different concentrations of cadmium.

The similar electrochemical behaviour is showed in all three cases, oxidation and the release of $\mathrm{Pb}(\mathrm{II})$ are at a negative potential value, indicating that the complex formed is less stable than those formed in the case of molecules B and C.

The determination of $\mathrm{Pb}(\mathrm{II}), \mathrm{Cd}(\mathrm{II})$ and $\mathrm{Cu}(\mathrm{II})$, respectively, in CPE modified with molecules A, B and C, was carried out by square wave voltammetry (SWV) after $10 \mathrm{~min}$ of accumulation in a solutions containing respectively, $\mathrm{Pb}(\mathrm{II}), \mathrm{Cd}(\mathrm{II})$ and $\mathrm{Cu}(\mathrm{II})$. The voltammograms are showed in Figures 8-10. In the three cases, two well-defined

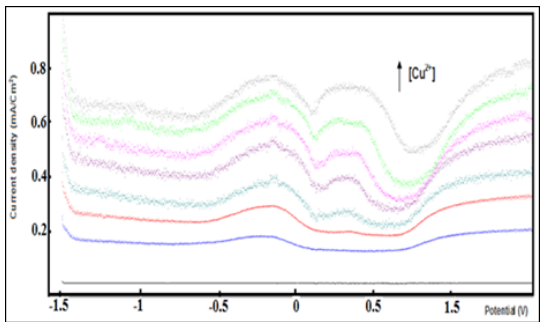

Figure 10: Square wave voltammograms obtained for CPE modified by molecule $\mathrm{C}$, for different concentrations of copper.

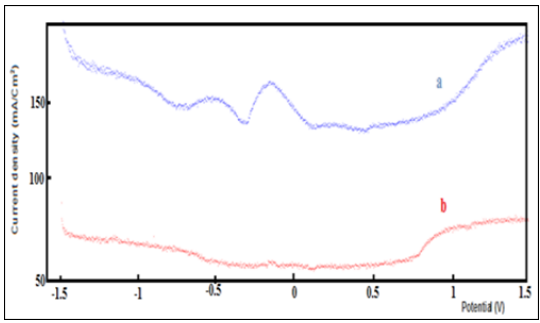

Figure 11: Square wave voltammograms obtained for CPE modified by molecule $\mathrm{A}$, for palladium solution.

and enhanced peaks are observed in MO-CPEs as compared to the unmodified one (Figure 11).

The increase in peaks current at the MO-CPEs demonstrates that the organic molecules play an important role in the accumulation process of studied heavy metals on the electrode surface.

The sensitivity of the method was studied by recording square wave voltammograms at different metals $\left(\mathrm{Pb}^{2+}, \mathrm{Cd}^{2+}\right.$ and $\left.\mathrm{Cu}^{2+}\right)$ concentrations. In all cases the $\mathrm{CPE}$ modified with studied organic molecules (A, B and C). A calibration plots obtained were linear and regression equations were different parameters obtained were given respectively in Tables 1 and 2.

The results obtained for the detection limits of MO-CPEs show that the organic films formed have highly sensitivity toward different heavy metals studied.

The relative standard deviations were found to be $6.8 \%$ and $5 \%$ respectively, for A-CPE for the determination of lead and $\mathrm{B}-\mathrm{CPE}$ for the determination of cadmium.

\section{Conclusion}

The Carbon Paste Electrode (CPE) was successfully modified with organic molecules. The detection of low levels of heavy metals was accomplished by using MO-CPEs with very good reproducibility. The method used is simple, time efficient and reproducible. The concentration of studied metals at the surface of the MO-CPEs is increased by the formation of metal complexes of the organic films.

\section{References}

1. Gao H, Qi X, Chen Y, Sun W (2011) Electrochemical deoxyribonucleic acid biosensor based on the self-assembly film with nanogold decorated on ionic liquid modified carbon paste electrode. Anal Chim Acta 704: 133-138.

2. Wang J (2003) Nanoparticle-based electrochemical DNA detection. Anal Chim Acta, 500: 247-257.

3. Gomdje VH, Ngono TRL, El S, Qouatli, Najih R, et al. (2013) Acta Tech Corv 5: $139-142$. 
Citation: Valery HG, Ngono TR, Saâdane H, Ennachete M, Khouili M, et la. (2013) Evaluation of Carbon Paste Electrodes Modified with Organic Molecules for the Analysis of Heavy Metals by Square Wave Voltammetry. Pharmaceut Anal Acta 4: 271. doi: 10.4172/2153-2435.1000271

4. Hernandez OE, Rodriguez IN, Hidalgo JLH, Reguera E (2007) Evaluation of carbon paste electrodes modified with 1-furoylthioureas for the analysis of cadmium by differential pulse anodic stripping voltammetry. Sensors and Actuators B 123: 488-494.

5. Kalcher K (1990) Chemically modified carbon paste electrodes in voltammetric analysis. Electroanalysis 2: 419-433.

6. Paneli MG (1993) Applications of adsorptive stripping voltammetry in the determination of trace and ultratrace metals. Electroanalysis 5: 355-373.
7. Kotkar R, Srivastava K(2006) Voltammetric determination of para-aminobenzoic acid using carbon paste electrode modified with macrocyclic compounds. Sensors and Actuators 119: 524-530.

8. Stockhausen V, Ghilane J, Martin P, Trippé-Allard G, Randriamahazaka H, et al. (2009) Grafting Oligothiophenes on Surfaces by Diazonium Electroreduction: A Step toward Ultrathin Junction with Well-Defined Metal/Oligomer Interface. Am Chem Soc 131: 14920-14927. 